\title{
Effect of Varying Steel Fiber Content on Strength and Permeability Characteristics of High Strength Concrete with Micro Silica
}

\author{
Babar Ali ${ }^{1}{ }^{\oplus}$, Rawaz Kurda ${ }^{2,3,4, *}$, Bengin Herki ${ }^{5,6}$, Rayed Alyousef ${ }^{7}\left(\mathbb{0}\right.$, Rasheed Mustafa ${ }^{8}$, \\ Ahmed Mohammed ${ }^{9}$, Ali Raza ${ }^{10}$ D , Hawreen Ahmed 2,3,4 and Muhammad Fayyaz Ul-Haq ${ }^{1}$ \\ 1 Department of Civil Engineering, COMSATS University Islamabad-Sahiwal Campus, Sahiwal 57000, \\ Pakistan; babar.ali@cuisahiwal.edu.pk (B.A.); m.fayyaz@cuisahiwal.edu.pk (M.F.U.-H.) \\ 2 Department of Highway and Bridge Engineering, Technical Engineering College, Erbil Polytechnic \\ University, Erbil 44001, Iraq; Hawreen.a@gmail.com \\ 3 Scientific Research and Development Center, Nawroz University, Duhok 42001, Iraq \\ 4 CERIS, Civil Engineering, Architecture and Georresources Department, Instituto Superior Técnico, \\ Universidade de Lisboa, Av. Rovisco Pais, 1049-001 Lisbon, Portugal \\ 5 Department of Civil Engineering, College of Science and Engineering, Bayan University, Erbil 44001, Iraq; \\ bengin.awdel@bnu.edu.iq \\ 6 Department of Civil Engineering, Faculty of Engineering, Soran University, Soran 44008, Iraq \\ 7 Department of Civil Engineering, College of Engineering, Prince Sattam bin Abdulaziz University, Alkharj \\ 16273, Saudi Arabia; r.alyousef@psau.edu.sa \\ 8 Department of Environmental Engineering, College of Engineering, Knowledge University, Erbil 44001, Iraq; \\ rasheed1954@yahoo.com \\ 9 Civil Engineering Department, College of Engineering, University of Sulaimani, Sulaymaniyah 46001, Iraq; \\ ahmed.mohammed@univsul.edu.iq \\ 10 Department of Civil Engineering, Pakistan Institute of Engineering and Technology, Multan 66000, Pakistan; \\ aliraza@piet.edu.pk \\ * Correspondence: rawaz.kurda@tecnico.ulisboa.pt; Tel.: +96-47505834949
}

Received: 26 November 2020; Accepted: 14 December 2020; Published: 16 December 2020

check for updates

\begin{abstract}
For the efficient and durable design of concrete, the role of fiber-reinforcements with mineral admixtures needs to be properly investigated considering various factors such as contents of fibers and potential supplementary cementitious material. Interactive effects of fibers and mineral admixtures are also needed to be appropriately studied. In this paper, properties of concrete were investigated with individual and combined incorporation of steel fiber (SF) and micro-silica (MS). SF was used at six different levels i.e., low fiber volume ( $0.05 \%$ and $0.1 \%)$, medium fiber volume $(0.25 \%$ and $0.5 \%)$ and high fiber volume (1\% and $2 \%)$. Each volume fraction of SF was investigated with $0 \%, 5 \%$ and $10 \%$ MS as by volume of binder. All concrete mixtures were assessed based on the results of important mechanical and permeability tests. The results revealed that varying fiber dosage showed mixed effects on the compressive (compressive strength and elastic modulus) and permeability (water absorption and chloride ion penetration) properties of concrete. Generally, low to medium volume fractions of fibers were useful in advancing the compressive strength and elastic modulus of concrete, whereas high fiber fractions showed detrimental effects on compressive strength and permeability resistance. The addition of MS with SF is not only beneficial to boost the strength properties, but it also improves the interaction between fibers and binder matrix. MS minimizes the negative effects of high fiber doses on the properties of concrete.
\end{abstract}

Keywords: mechanical properties; fiber-reinforced concrete; permeability; durability; tensile strength; micro-silica/silica fume; steel fiber 


\section{Introduction}

Plain cement concrete (PCC) is the most versatile construction material owing to its multiple benefits i.e., high compressive strength, cost-efficient, in-situ formability, thermal and electrical insulation, imperviousness, etc. Ingredients and mix design of PCC can be changed to obtain different types of concrete that suit different structural loadings and environments. To further raise the importance of conventional concrete, several performance-related issues need to be resolved. PCC generally performs weakly under tensile loadings. Its splitting tensile strength (STS) is very low compared to its compressive strength (CS). According to Ali and Qureshi [1,2] and Koushkbaghi et al. [3] PCC has a STS/CS ratio of about 7-9.5\%. Zain et al. [4] showed that the STS/CS ratio decreases as the strength class of concrete is upgraded, therefore, high strength PCCs are more vulnerable to brittle failure than normal strength PCCs. PCC has low energy absorption capacity (or toughness) under both tensile and compressive loadings $[5,6]$. It undergoes a sudden failure after carrying the load beyond its peak capacity and it has very low residual strength (almost negligible compared to fiber-reinforced concrete) [7]. Mechanical performance of PCC undergoes significant degradation with time when subjected to environmental stresses (freeze-thaw) [8] and weathering actions of water and acid attack [9]. Due to the inherent weakness of PCC under tensile loadings, large structural dimensions cannot be avoided unless it is reinforced with some high strength material i.e., steel rebars, glass fiber-reinforced polymers (GFRP) bars, carbon fiber-reinforced polymer (CFRP) bars, etc.

Nowadays, fibers are being used as a discrete 3-dimensional reinforcement to overcome the deficiency of PCC in tensile strength. With the addition of proper fiber-type in concrete, initiation and proliferation cracks under both tensile and compressive loads can be controlled or delayed. Many types of reinforcements are available commercially that own their application-specific characteristics e.g., carbon fiber, steel fiber (SF), glass fiber, polypropylene fiber [10] organic fibers [11], carbon nano-tubes $[12,13]$ etc. Tensile reinforcements disperse throughout the PCC matrix, bridge the microcracking $[12,13]$. Considering the mechanical performance of concrete, $\mathrm{SF}$ is by far more superior fiber compared to other industrial fibers [10]. SF has a very high tensile strength of over $1200 \mathrm{MPa}$ and an elastic modulus of about $200 \mathrm{GPa}$. The literature confirms its vitality as a superior reinforcement material that ensures satisfying tensile, compressive, flexural and shear strength properties [14-17]. By improving the strength per unit quantity of material, SF-reinforced concrete (SFRC) shows lower economic and environmental impact compared to PCC [14].

There are several issues relevant to the underutilization of SF in fiber-reinforced concrete that must be addressed. According to Lee et al. [18], the primary reason for the failure of SF-Reinforced Concrete (SFRC) is the failure linked to the interface between fiber and binder matrix of the concrete. Two different types of failures are linked to SFRCs when the underutilized fiber is separated from the binder matrix [19]. The first type of failure occurs at the interface between the fiber and binder matrix, whereas another type of failure occurs in the adhering binder matrix. Both of these failures lead to under-utilization of matrix and full tensile strength potential of fibers, and consequently leading to cracking of concrete. Therefore, bond strength between fibers and binder matrix plays a significant role in defining the tensile capacity of fibrous composites.

The effect of SF on the properties of the fibrous composite also depends on the dosage of fiber. There is a consensus among researchers that the tensile and bending capacity of concrete improves the increasing fiber dosage ( 0 to $2 \%$ by volume fraction) [3,9,20-23], but the literature has shown the mixed effects of varying SF dosage on the compressive behavior of concrete. Some studies [23,24] report that SF induces porosity into concrete therefore, compressive strength and elastic modulus of concrete undergoes degradation with the rising fiber volume. Whereas, there are studies $[3,9,21]$ which have shown positive effects of SF on compressive behavior of concrete. The improvements in compressive strength were attributed to the increased stiffness and confinement of concrete $[3,9,21]$. However, a consensus is found among findings of the researchers that SF is beneficial to compression toughness of concrete $[5,23,25,26]$. 
There are some issues related to application of SFRC that are vital to be understood and resolved. The reasons behind the mixed effects (positive, negative or inconsiderable) of SF dose on compressive strength of concrete are still needed to be understood for the effective use of fibers under compression loadings. Moreover, poor bond strength between fiber and binder matrix reduces the utilization of full potential of SF. It is essential to investigate the influence of such materials (i.e., MS) on SFRC that help in strengthening binder matrix and improve the dispersion of fibers $[2,10]$. This study is designed to evaluate the effects of varying SF dosage on the properties of a high strength concrete. To investigate the role of bond strength at interfacial zone between fiber and matrix, the effect of SF dosage was also explored with and without micro-silica (MS). SF was used at six different levels i.e., low fiber volume $(\mathrm{Vf}=0.05 \%$ and $0.1 \%)$, medium fiber volume $(\mathrm{Vf}=0.25 \%$ and $0.5 \%)$ and high fiber volume $(\mathrm{Vf}=1 \%$ and $2 \%$ ). Each dose of SF was investigated with $0 \%, 5 \%$ and $10 \%$ MS as by volume of binder. MS is an excellent consumer of portlandite $\mathrm{CH}$ (in pozzolanic reaction, that strengthens the binder matrix and improves the bond strength of fibers [27]. Concrete mixtures were assessed based on the results of basic mechanical and permeability tests. The results of this study provide a useful information on the selection of SF dose for the optimum mechanical and durability performance. Moreover, experimental results favor the use of MS to maximize the utilization of SF under compressive and tensile forces.

\section{Materials and Methods}

\subsection{Materials}

Conventional and supplementary materials used for the production of concrete mixtures are explained in this section. Type I general purpose cement (Bestway 53 Grade, Haripur, Pakistan) was used as the main binder as per specifications of ASTM C150 [28]. Micro-silica (also known as silica fume obtained from Jaza Minerals, Karachi, Pakistan) containing $90-94 \%$ silica was used as a partial cement substitute. Properties of cement and micro-silica can be assessed from the study of Ali et al. [2]. Siliceous sand from the Lawrancepur quarry (Attock, Pakistan) was used as fine aggregate. Dolomite sandstone of Kirana-hills of Sargodha was used as the coarse aggregate. The maximum aggregate size of coarse and fine aggregate is $12.5 \mathrm{~mm}$ and $4.75 \mathrm{~mm}$. The distribution of different particle sizes in both coarse and fine aggregates is shown in Figure 1. Characteristics of aggregates are given in Table 1.

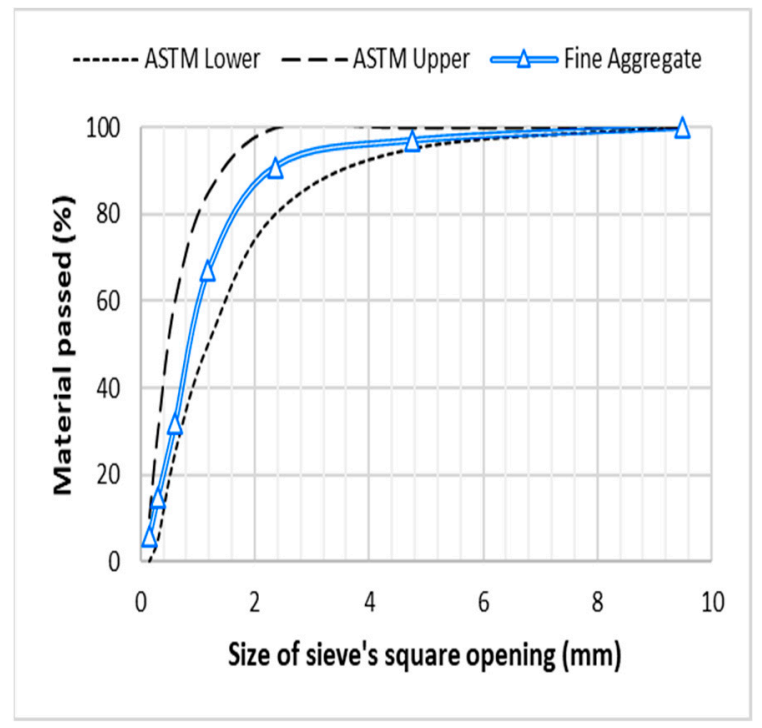

(a)

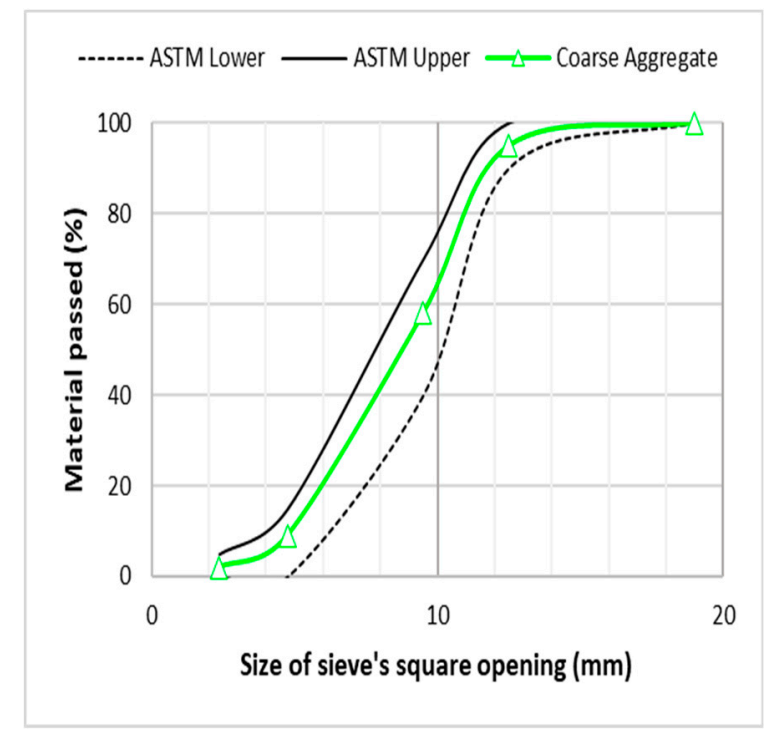

(b)

Figure 1. Gradation of (a) Siliceous sand/fine aggregate and (b) crushed dolomite limestone/coarse aggregate. 
Table 1. Characteristics of aggregates.

\begin{tabular}{|c|c|c|c|c|c|c|}
\hline Aggregate Type & Material & $\begin{array}{l}\text { Dry Rodded } \\
\text { Density }\end{array}$ & $\begin{array}{c}\text { Water } \\
\text { Absorption (\%) }\end{array}$ & $\begin{array}{l}10 \% \text { Fine } \\
\text { Value (kN) }\end{array}$ & $\begin{array}{l}\text { Specific } \\
\text { Gravity }\end{array}$ & $\begin{array}{c}\text { Maximum } \\
\text { Aggregate Size }\end{array}$ \\
\hline & & 1615 & 0.97 & - & 2.67 & 4.75 \\
\hline Coarse Aggregate & Dolomite-sandstone & 1519 & 0.65 & 148 & 2.68 & 12.5 \\
\hline
\end{tabular}

Hooked steel fiber (SF) was studied as a discrete reinforcement in concrete. It has tensile strength of $750 \mathrm{MPa}$ and a density of $7750 \mathrm{~kg} / \mathrm{m}^{3}$. It was sourced from Dramix@ (Zwevegem, Belgium). SF has a length of $30 \mathrm{~mm}$ and a diameter of $0.38 \mathrm{~mm}$. Its overview is shown in Figure 2. To control the loss of workability with a rising dose of SF, Viscorete 3110 (Sika Chemicals, Lahore, Pakistan) was used as an ultra-high range plasticizer. Tap water free from organic/inorganic impurities was used during the mixing and for curing as well.

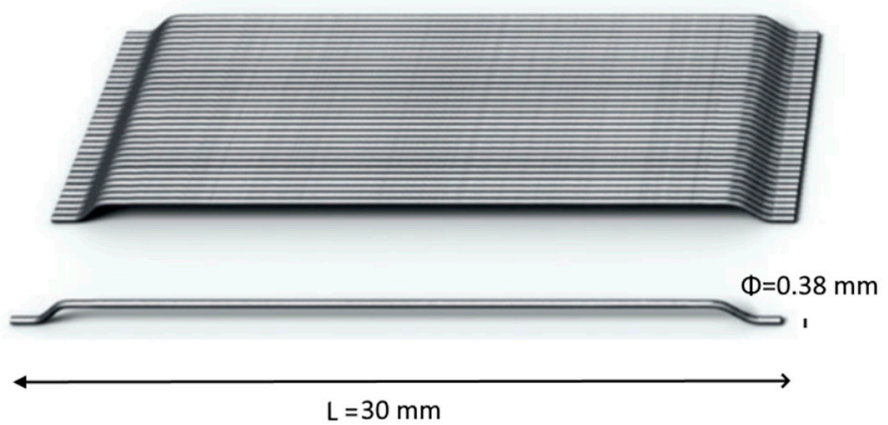

Figure 2. Overview of SF.

\subsection{Design of Concrete Mixtures}

A total of 21 concrete mixes were studied in this research. Six different doses $(\mathrm{Vf}=0.05,0.1,0.25$, $0.5,1$ and $2 \%$ ) of SF were used to produce fiber-reinforced concretes. SF volumes were selected to observe the effects of a wide range of fiber doses on the properties of concrete. Fibers were used as by volume fraction of concrete (i.e., $1 \% \mathrm{Vf}$ of $\mathrm{SF}=78 \mathrm{~kg}$ of SF). Each fiber dosage is investigated with $0 \%$, $5 \%$ and $10 \%$ micro-silica (MS). MS serves as the matrix-strengthening agent by producing calcium silicate hydrate gels from the free portlandite- $\mathrm{CH}$ a by-product from the hydration of cement. Plain concretes were also produced with and without MS and served as reference mixes. Composition and mix proportioning of all concrete mixtures are provided in Table 2.

Mixing of all concretes was done in a mechanical mixer having adjustable rotation speed. In the first stage, aggregates and binder were dry mixed for $3 \mathrm{~min}$ at speed of $40 \mathrm{rpm}$. In the second stage, half of the mixer and water reducer were added to the mix and blending continued for $3 \mathrm{~min}$ at speed of $40 \mathrm{rpm}$. In the third stage, the remaining water was added to the mix, and mixing was done a high speed of $80 \mathrm{rpm}$ for $2 \mathrm{~min}$. In the last stage, SF was added to the concrete mix, and blending continued for the next $4 \mathrm{~min}$ at $80 \mathrm{rpm}$. After mixing, a slump test was performed to check the desired workability of mixes (i.e., slump between 80 and $110 \mathrm{~mm}$ ). Mixer continued to run at a slower speed of $20 \mathrm{rpm}$ until the casting of specimens was completed. 
Table 2. Design of concrete mixes.

\begin{tabular}{|c|c|c|c|c|c|c|c|c|c|c|}
\hline $\begin{array}{l}\text { Mix } \\
\text { No. }\end{array}$ & Mix ID & $\begin{array}{l}\text { MS } \\
(\%)\end{array}$ & SF (\%) & $\begin{array}{l}\text { Cement } \\
\left(\mathrm{kg} / \mathrm{m}^{3}\right)\end{array}$ & $\underset{\left(\mathrm{kg} / \mathrm{m}^{3}\right)}{\mathrm{MS}}$ & $\begin{array}{l}\text { Siliceous } \\
\text { Sand } \\
\left(\mathrm{kg} / \mathrm{m}^{3}\right)\end{array}$ & $\begin{array}{l}\text { Crushed } \\
\text { Limestone } \\
\left(\mathrm{kg} / \mathrm{m}^{3}\right)\end{array}$ & $\begin{array}{c}\mathrm{SF} \\
\left(\mathrm{kg} / \mathrm{m}^{3}\right)\end{array}$ & $\begin{array}{c}\text { Water } \\
\left(\mathrm{kg} / \mathrm{m}^{3}\right)\end{array}$ & $\begin{array}{l}\text { HWR } \\
\left(\mathrm{kg} / \mathrm{m}^{3}\right)\end{array}$ \\
\hline 1 & $\begin{array}{l}\text { MS0/SF0 } \\
\text { (Control) }\end{array}$ & \multirow{8}{*}{0} & 0.00 & 478 & 0 & 657 & 1077 & 0 & 185 & 2 \\
\hline 2 & MSO/SF0.05 & & 0.05 & 478 & 0 & 656 & 1076 & 4 & 185 & 2 \\
\hline 3 & MS0/SF0.1 & & 0.10 & 478 & 0 & 656 & 1076 & 8 & 185 & 2 \\
\hline 4 & MSO/SF0.25 & & 0.25 & 478 & 0 & 654 & 1074 & 20 & 185 & 2 \\
\hline 5 & MS0/SF0.5 & & 0.50 & 478 & 0 & 651 & 1071 & 39 & 185 & 3 \\
\hline 6 & MS0/SF1 & & 1.00 & 478 & 0 & 644 & 1064 & 78 & 185 & 3 \\
\hline 7 & MSO/SF2 & & 2.00 & 478 & 0 & 631 & 1051 & 156 & 185 & 3 \\
\hline 8 & MS5/SF0 & & 0.00 & 454 & 18 & 657 & 1077 & 0 & 185 & 2 \\
\hline 9 & MS5/SF0.05 & \multirow{6}{*}{5} & 0.05 & 454 & 18 & 656 & 1076 & 4 & 185 & 2 \\
\hline 10 & MS5/SF0.1 & & 0.10 & 454 & 18 & 656 & 1076 & 8 & 185 & 2 \\
\hline 11 & MS5/SF0.25 & & 0.25 & 454 & 18 & 654 & 1074 & 20 & 185 & 2 \\
\hline 12 & MS5/SF0.5 & & 0.50 & 454 & 18 & 651 & 1071 & 39 & 185 & 3 \\
\hline 13 & MS5/SF1 & & 1.00 & 454 & 18 & 644 & 1064 & 78 & 185 & 3 \\
\hline 14 & MS5/SF2 & & 2.00 & 454 & 18 & 631 & 1051 & 156 & 185 & 3 \\
\hline 15 & MS10/SF0 & \multirow{7}{*}{10} & 0.00 & 430 & 36 & 657 & 1077 & 0 & 185 & 2 \\
\hline 16 & MS10/SF0.05 & & 0.05 & 430 & 36 & 656 & 1076 & 4 & 185 & 2 \\
\hline 17 & MS10/SF0.1 & & 0.10 & 430 & 36 & 656 & 1076 & 8 & 185 & 2 \\
\hline 18 & MS10/SF0.25 & & 0.25 & 430 & 36 & 654 & 1074 & 20 & 185 & 2 \\
\hline 19 & MS10/SF0.5 & & 0.50 & 430 & 36 & 651 & 1071 & 39 & 185 & 3 \\
\hline 20 & MS10/SF1 & & 1.00 & 430 & 36 & 644 & 1064 & 78 & 185 & 3 \\
\hline 21 & MS10/SF2 & & 2.00 & 430 & 36 & 631 & 1051 & 156 & 185 & 3 \\
\hline
\end{tabular}

MS: Micro-Silica; SF: Steel Fiber; HWR: High-range Water Reducer.

\subsection{Sample Preparation and Testing Techniques}

All specimens were cast in standard steel molds and protected with a waterproof membrane for $24 \mathrm{~h}$ setting immediately after casting. After setting, specimens were cured in tap water for 28-days at room temperature conditions. All mixes were tested for three important mechanical parameters i.e., compressive strength (CS), modulus of elasticity (MOE), and splitting tensile strength (STS). For CS, $100 \varphi \mathrm{mm} \times 200 \mathrm{~mm}$ cylindrical specimens were tested as per ASTM C39 [29]. To determine CS, specimens were tested under compressive-hydraulic press at the rate of $0.3 \mathrm{MPa} / \mathrm{s}$. The static MOE of each mix was determined according to ASTM C469 [30]. MOE test was conducted on the specimens of $150 \varphi \mathrm{mm} \times 300 \mathrm{~mm}$ at the stress-rate of $0.15 \mathrm{MPa} / \mathrm{s}$. The strain data (deformation characteristics) was recorded using compressometer-extensometer. To evaluate STS, $100 \varphi \mathrm{mm} \times 200 \mathrm{~mm}$ specimens were tested following ASTM C496 [31]. The splitting-load was applied at the stress rate of $0.015 \mathrm{MPa} / \mathrm{s}$ on the specimen to determine STS. All mechanical tests were performed in a controls compression testing machine with a loading capacity of $3000 \mathrm{kN}$. To understand the effects of varying SF and MS contents on the durability of concrete, two permeability-related durability indicators were evaluated i.e., water absorption and chloride ion penetration. To test for water absorption (WA) capacity, $100 \varphi \mathrm{mm} \times 50 \mathrm{~mm}$ concrete disc specimen of each mix was tested following ASTM C642 [32]. To determine chloride ion penetration (CIP) resistance of each mix, an immersion technique was adopted as explained by the authors [2]. For the CIP test, a $100 \mathrm{~mm} \times 100 \mathrm{~mm}$ cylindrical specimen was first cured in normal water for 28 days. Then the specimen was immersed in a $10 \% \mathrm{NaCl}$ solution for 56 days. After conditioning in chloride solution, the specimen was split, and the failed surface of the specimen was sprayed with $0.1 \mathrm{~N} \mathrm{AgNO}_{3}$ solution to observe the depth of CIP. The further detailed procedure for CIP testing can be assessed from studies [2,33]. All the results presented in this research are the mean values of the three results of each concrete mixture. The schedule of casting and testing is shown in Table 3. 
Table 3. Overview of mechanical and permeability testing methods and schedule.

\begin{tabular}{cccc}
\hline Property & Standard Followed & Size of Specimen & Age of Testing \\
\hline Compressive Strength (MPa) & ASTM C39 & $100 \varphi \mathrm{mm} \times 200 \mathrm{~mm}$ cylinder & 28 days \\
Modulus of Elasticity (MPa) & ASTM C469 & $150 \varphi \mathrm{mm} \times 300 \mathrm{~mm}$ cylinder & 28 days \\
Splitting Tensile Strength (MPa) & ASTM C496 & $100 \varphi \mathrm{mm} \times 200 \mathrm{~mm}$ cylinder & 28 days \\
Water Absorption (\%) & ASTM C642 & $100 \varphi \mathrm{mm} \times 50 \mathrm{~mm}$ disc & $\begin{array}{c}28 \text { days } \\
\text { Chloride Ion Penetration (mm) }\end{array}$ \\
& Ali et al. [2] & $100 \varphi \mathrm{mm} \times 100 \mathrm{~mm}$ cylinder & $\begin{array}{c}28 \text { days curing }+56 \text { days of } \\
\text { condition in NaCl solution }\end{array}$ \\
\hline
\end{tabular}

\section{Results and Discussion}

\subsection{Compressive Strength (CS)}

Figure 3 shows the effect of varying SF dose on the CS of concrete. Figure $3 b$ shows the net age change in CS with the varying SF dose. These results show a mixed effect of SF on CS at different doses. CS goes on increasing when the SF dose changed from 0 to $0.25 \%$. Further increasing SF beyond $0.25 \%$, CS starts reducing, and at $2 \% \mathrm{SF}, \mathrm{CS}$ of fibrous concrete is lesser than that of the plain concrete. Three different causes contribute to CS property due to the inclusion of fibers. The first cause is related to the confinement effect of fibers that increases the stiffness of concrete and it is known to positively affect the CS $[10,34,35]$. The second phenomenon is related to the entrainment of additional ITZs in concrete that has a detrimental effect on the CS. The introduction of a high number of ITZs contributes to porosity and permeable channels into the concrete and ITZs act as a weak link in the fibrous composite. The third phenomenon pertains to the resistance of cracking to the propagation of micro and macro-cracks; thus, it is known to improve the compressive stiffness of concrete. The first and third phenomenon prevails at $0.1-0.25 \%$ dose of SF, therefore, CS shows improvement due to fiber addition, whereas, at high fiber doses, a high number of ITZs introduction facilitate crack propagation and it adds to the total porosity of concrete.

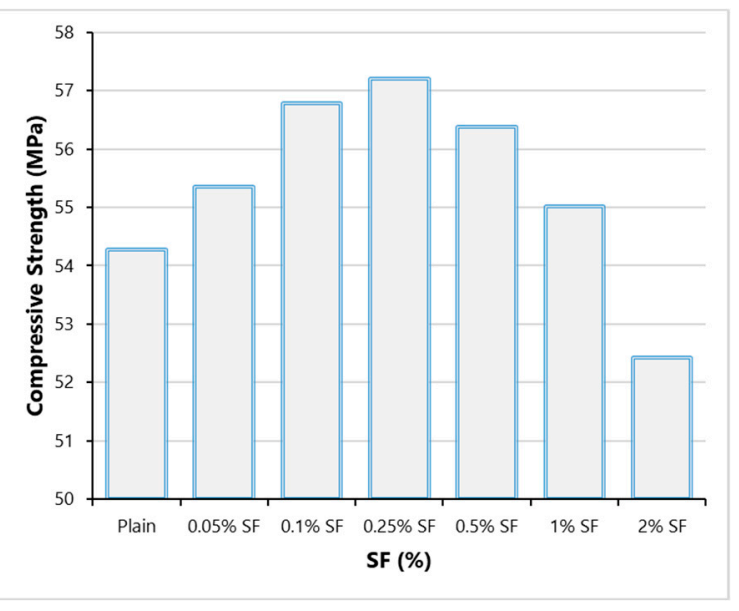

(a)

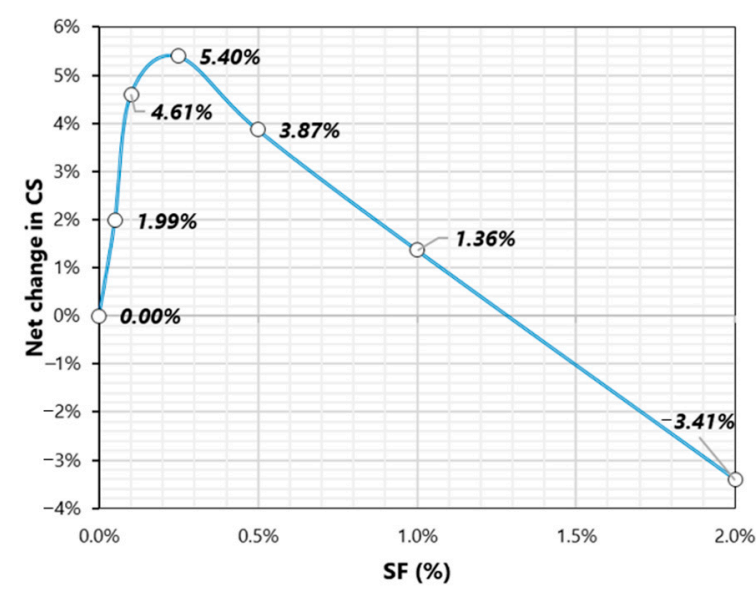

(b)

Figure 3. Compressive strength (CS) results (a) Variation of CS with SF dosage (b) Net change in CS with varying SF dosage.

Figure 4 shows the effect of MS on CS results of high strength concrete at different doses of SF. Figure $4 \mathrm{~b}$ shows the effect of varying SF dose on CS at the levels of $0 \%, 5 \%$ and $10 \%$ MS. MS shows a positive effect on compressive strength concrete due to its ability to produce calcium silicate hydrate gels in pozzolanic reactive with free portlandite. The strengthening of the binder leads to improvement in the bond strength of fibers and matrix, that is why a clear difference (Figure $4 \mathrm{~b}$ ) between "net change" of SF mixes with and without MS. For example, at $0.25 \%$ SF the net changes in CS at $0 \%$, 
$5 \%$ and $10 \%$ MS are $5.4 \%, 7.03 \%$ and $10.37 \%$, respectively. MS also minimizes the negative effect of high fiber volumes (i.e., $2 \% \mathrm{SF}$ ) on CS. This can be credited to the strengthening of the bond at ITZ, which enhances the utilization of fibers in compression. It is confirmed from the results that the combined incorporation of $10 \% \mathrm{MS}$ and $0.5 \% \mathrm{SF}$ can increase the CS by more than $20 \%$. It is verified by the literature that MS addition does not only contribute to the bond strength of fibers but it also improves the dispersion of fibers [27,36,37]. Therefore, it can be said that SF and MS have synergistic effects on the properties of concrete.

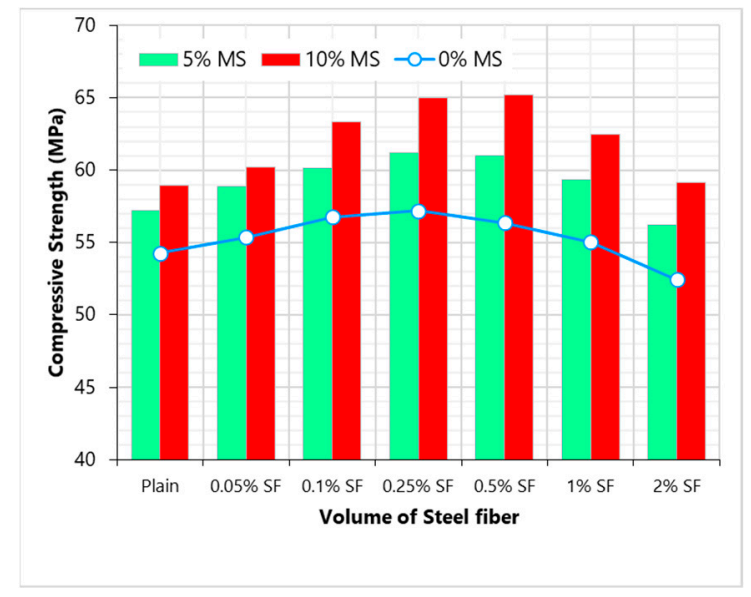

(a)

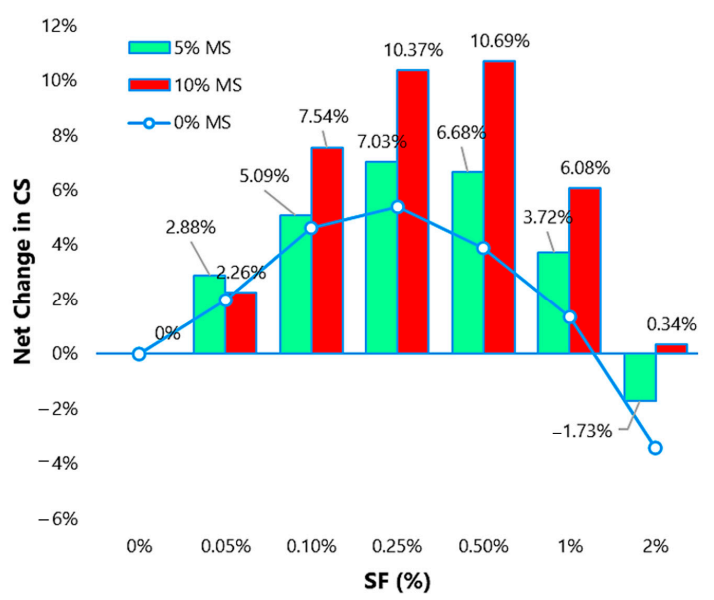

(b)

Figure 4. Compressive strength results (a) effect of MS on CS with varying SF dosage (b) effect of MS on the net change in CS with varying SF dosage.

\subsection{Modulus of Elasticity (MOE)}

Figure 5 shows the effect of SF on the MOE of concrete. MOE linearly increases when the SF dose changes from 0 to $0.5 \%$. Figure $5 \mathrm{~b}$ shows the effect of SF dose on the net change in MOE. The improvements in MOE at $0.05-0.5 \%$ can be ascribed to increment in the confinement of specimen under compression that helps in the utilization of the full potential of the concrete matrix. Beyond $0.5 \% \mathrm{SF}$, MOE starts degrading similar to CS. This shows that for given high-strength concrete the optimum dose of SF for optimum MOE is $0.5 \%$. As already explained, high fiber doses can increase the number of ITZs in concrete which leads to the reduction in compression stiffness of concrete. A slight increase in porosity of concrete due to fibers (higher than $0.5 \%$ ) can also damage the MOE considerably [38]. This finding is in line with the study of Xie et al. [24]. It was observed that during compression testing, mixes with high fiber doses showed more ductile failure before collapsing completely unlike the mixes with smaller doses. A linear increase in energy absorption capacity was observed with the rise in SF dose. Ou et al. [39] reported that the main role of SF is prominent in compression toughness of concrete (post-peak load behavior) because, before peak load in the determination of MOE, fibers are not activated.

In Figure 6, the effect of MS content is shown on the MOE of concrete. Figure $6 \mathrm{~b}$ shows the net change in MOE due to varying dose of SF at 0,5 and $10 \%$ replacement levels of MS. A clear improvement is noticed in the MOE of concrete due to MS addition. This is credited to (1) the improved packing density of binder particles and (2) the pozzolanic reaction that consumes free lime. MOE concrete with $10 \%$ MS is $11 \%$ higher than that of the plain concrete without MS. Figure $6 \mathrm{~b}$ shows that MS enhances the utilization of fibers. Moreover, MS minimizes the negative effect of high SF volume on MOE. The combined incorporation of MS and SF shows synergistic behavior. For example, $0.5 \% \mathrm{SF}$ and $10 \% \mathrm{MS}$ individually leads to improvement of $3.4 \%$ and $7 \%$, respectively. But simultaneous incorporation of both MS and SF improves the MOE by $14.8 \%$. This is true for all mixes made with both MS and SF. 


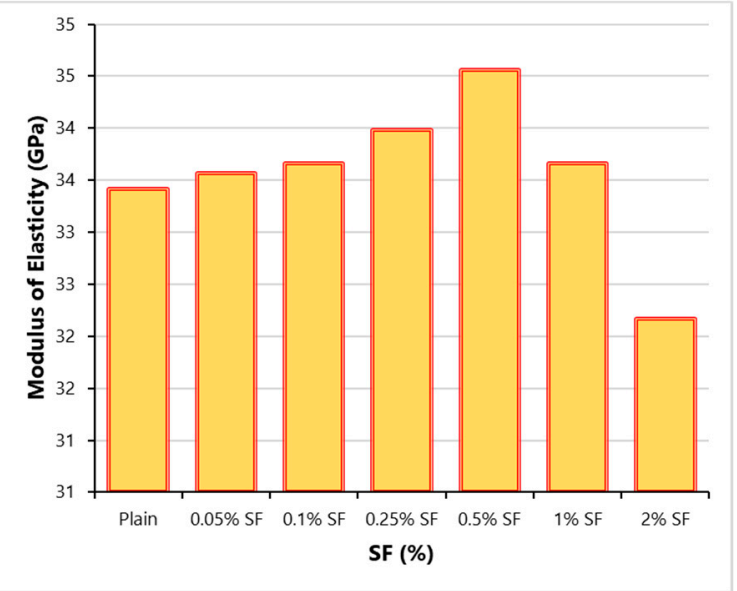

(a)

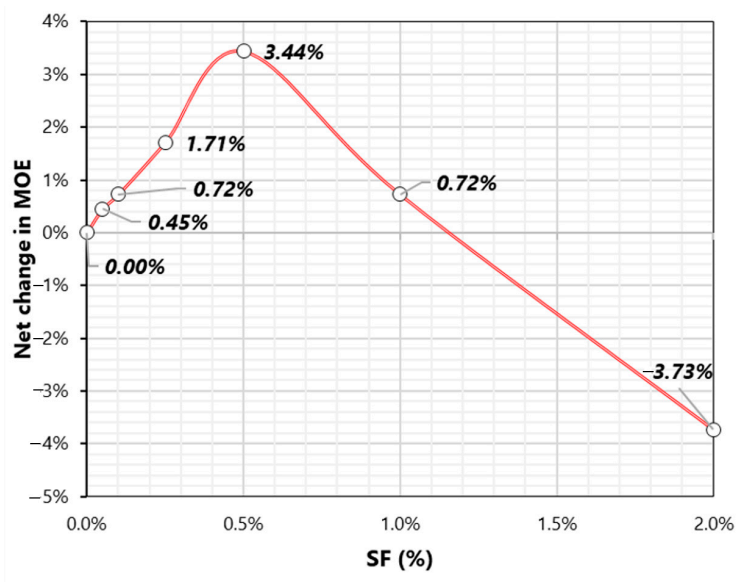

(b)

Figure 5. Modulus of elasticity (MOE) results (a) Variation of MOE with SF dosage (b) Net change in MOE with varying SF dosage.

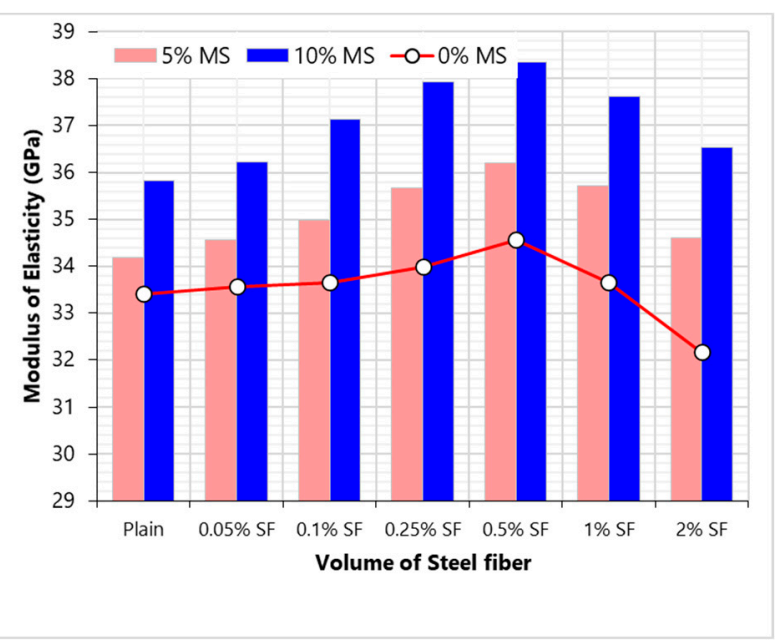

(a)

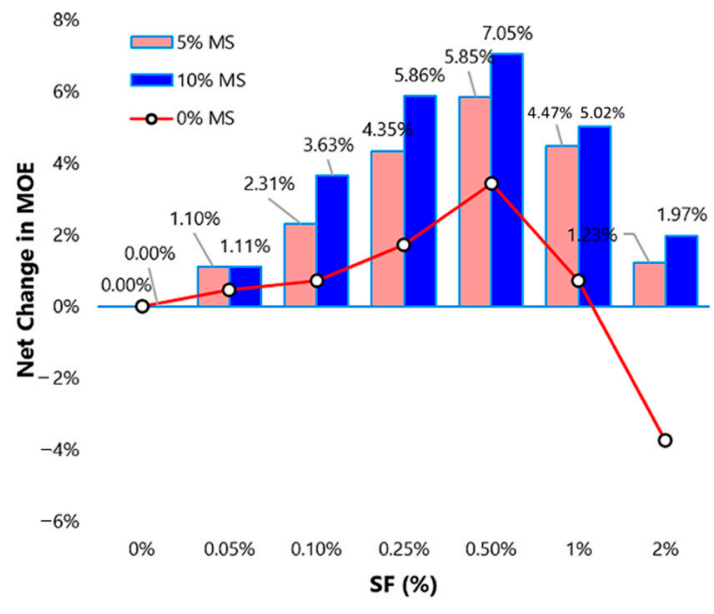

(b)

Figure 6. Modulus of elasticity (MOE) results (a) effect of MS on MOE with varying SF dosage (b) effect of MS on the net change in MOE with varying SF dosage.

From the results of CS and MOE, it is quite clear that both of these mechanical properties show a similar response to varying SF and MS contents. Therefore, both parameters can predict each with great accuracy. Since MOE is difficult to determine in the laboratory; therefore, it is predicted usually from CS. The relationship between MOE and half power of CS is shown in Figure 7. This relationship (Equation (1)) is drawn without considering the impact of SF or MS content:

$$
\mathrm{MOE}=7007 \sqrt{\mathrm{CS}}-18500
$$

where $\mathrm{MOE}=$ modulus of elasticity $(\mathrm{MPa}) ; \mathrm{CS}=$ compressive strength $(\mathrm{MPa})$. 


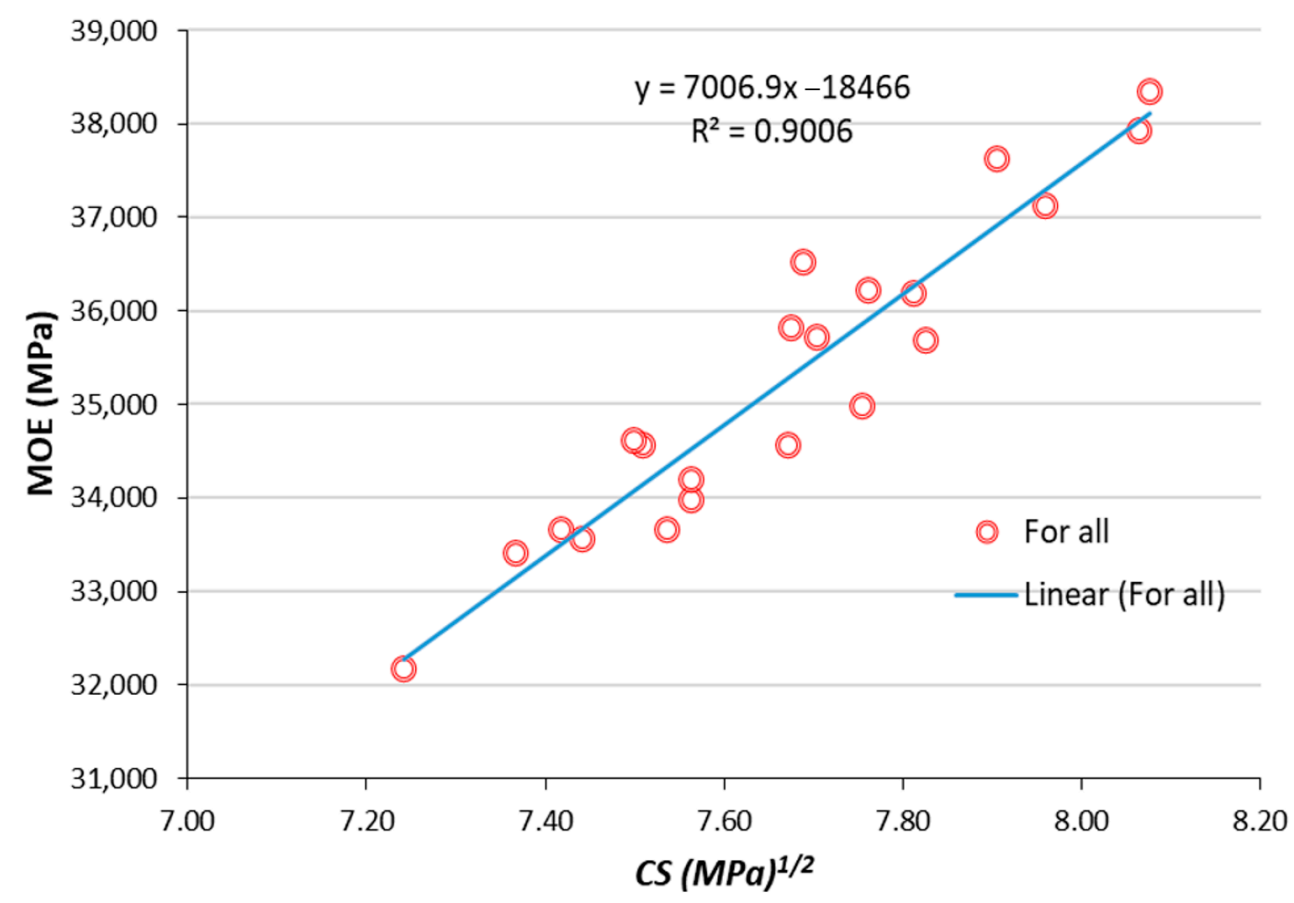

Figure 7. Relationship between MOE and $\mathrm{CS}^{1 / 2}$.

\subsection{Splitting Tensile Strength (STS)}

STS in an estimate of true tensile strength of concrete. Due to the complexity of measuring the true tensile strength under the direct tension test, STS provides a simpler measurement of the tensile strength of cementitious materials. Figure 8 shows the effect of varying SF content on STS. Unlike results of CS and MOE, STS does not show a mixed response to increasing the dose of SF. This is because, under tensile load, fibers become active way before the failure at peak load; therefore, stretching action on concrete is resisted by both concrete matrix and fibers. Figure 8 shows that the net change in STS due to SF addition is very huge compared to that observed in the results of MOE and CS. STS achieves more than 3 times positive gain compared to CS and MOE at each dose of SF. This confirms that fibers are more useful in tensile stiffness than they are in the compressive stiffness of concrete.

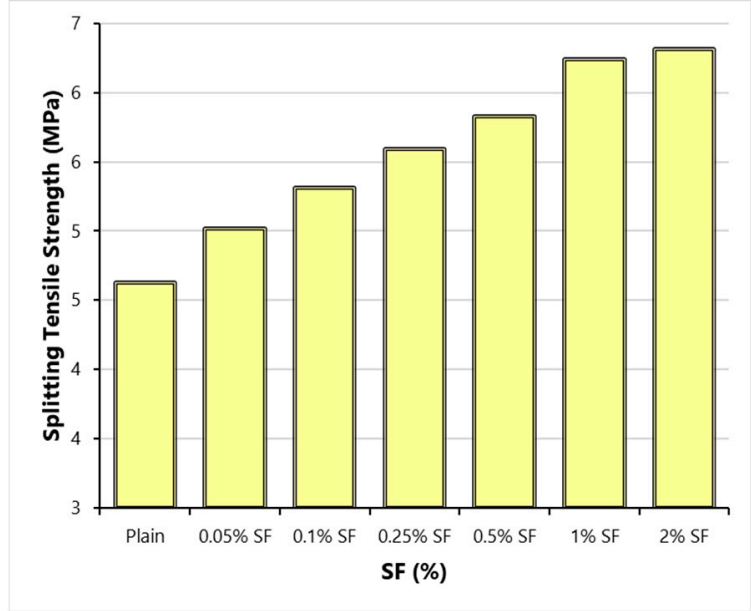

(a)

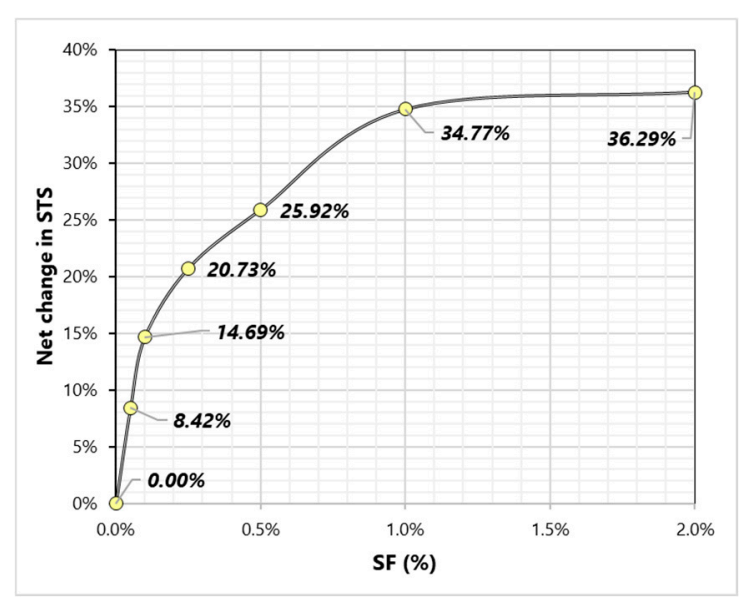

(b)

Figure 8. Splitting-tensile strength (STS) results (a) Variation of STS with SF dosage (b) Net change in STS with varying SF dosage. 
MS addition provides a little advancement in the tensile strength, see Figure 9. Since MS strengthens the binder matrix, some small improvements can be anticipated in the STS. The filling effect of MS particles cannot contribute to STS, only the pozzolanic reaction between portlandite and silica strengthens the concrete matrix against tensile stresses [40]. A clear view of the synergistic effect of MS and SF on the STS can be seen in Figure 9. MS addition improves the net gain due to fibers by more than $30 \%$. Densification of the matrix leads to an efficient transfer of tensile stresses to fiber-filaments; thus, MS addition improves the utilization of fibers. The results show that using MS along with SF can help in yielding $20 \%$ more STS than that could be achieved without MS. These results have important implications for fiber-reinforced concrete/composites. Since fibers are very expensive materials, their full utilization is very necessary to design cost and performance efficient structures. Therefore, MS and other high-performance mineral admixtures can help in enhancing the utilization of fibers.

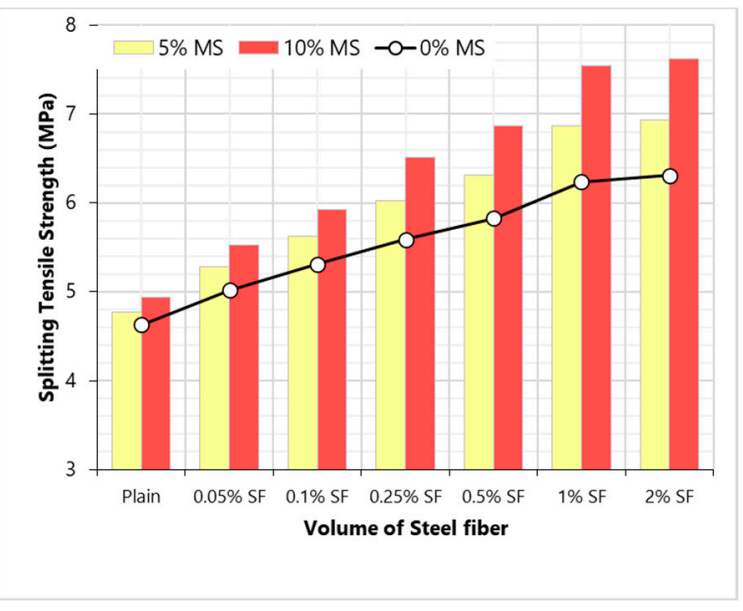

(a)

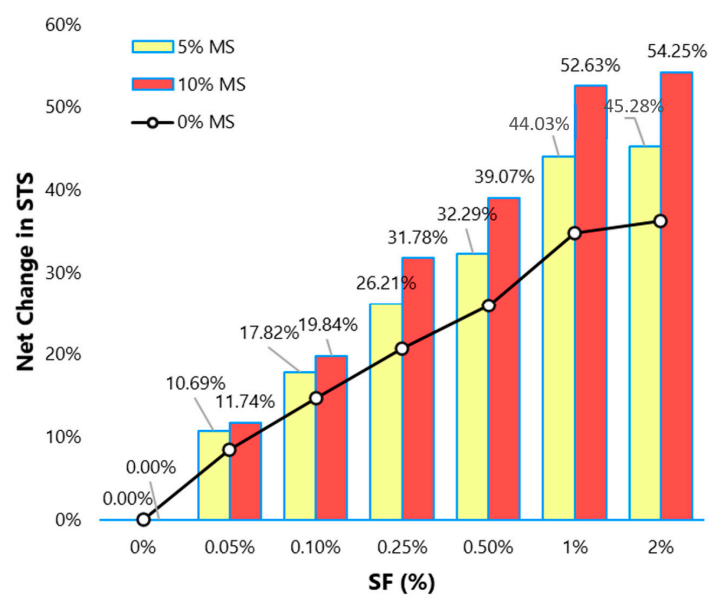

(b)

Figure 9. Splitting-tensile strength (STS) results (a) effect of MS on STS with varying SF dosage (b) effect of MS on the net change in STS with varying SF dosage.

For plain concrete, STS can be fairly correlated with CS or MOE. But for fibrous concrete STS cannot be correlated with CS or MOE, see Figure 10. As, activation of fibers during compression mostly starts near or after the peak load loads; therefore, fibers do not contribute a great deal towards the advancement of CS or MOE. Whereas, under tension, fibers activate way before peak load; therefore, concretes show a huge STS change with fiber addition. Under tension, fibers do not only contribute to the peak strength of concrete, but they are also useful in the post-peak load resistance. CS, MOE, and STS of each mix are correlated in Figure 10, without considering the role of SF dose. This surface plot shows a general trend that each mechanical parameter is directly proportional to each other but with a huge scatter $(\mathrm{R} 2<0.6)$.

\subsection{Water Absorption (WA)}

WA capacity of concrete represents its water-permeable volume of voids. High WA generally indicates high porosity. The effect of SF on the WA capacity of each mix is shown in Figure 11. WA undergoes mixed changes with the rising dose of SF. Small fractions of SF cause minor reductions in the WA capacity of concrete, whereas, at high doses, SF, WA absorption of fibrous concrete is slightly higher than that of the plain concrete. Both positive [21,41] and negative [42] effects of SF on WA has been reported in the literature. No study in the literature has examined the permeability characteristics of SF-reinforced concretes considering a wide range of fiber dosage. Fibers can control micro-cracking during the evolution of cementitious compounds in concrete. These can restrict the 
plastic and temperature shrinkage cracking which ultimately improves the permeability resistance of concrete. At the same time, fiber addition increases the number of ITZs in concrete. Poor bond at ITZs favor permeability, hence it increases of WA capacity. Apparently, at low fiber volumes, controlled shrinkage leads to reduction in WA capacity and the role of ITZs is not very dominant at low fiber volumes. But as the fiber volume increases, the number of weak ITZs favor permeability and increase the WA. The minimum WA is observed at $0.1 \% \mathrm{SF}$, whereas maximum WA is noticed at $2 \% \mathrm{SF}$.

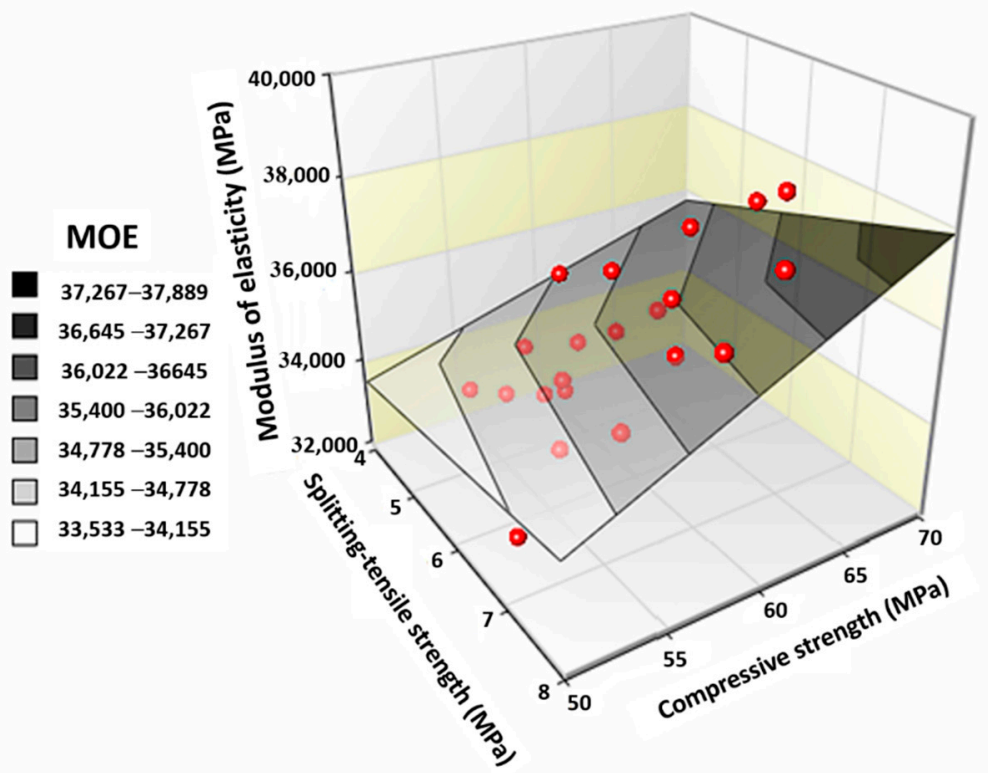

Figure 10. Correlation between mechanical properties (MOE, STS and CS).

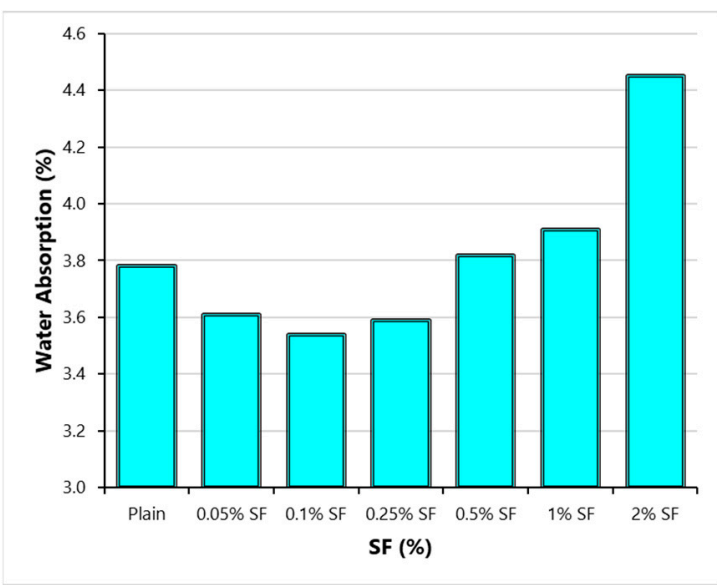

(a)

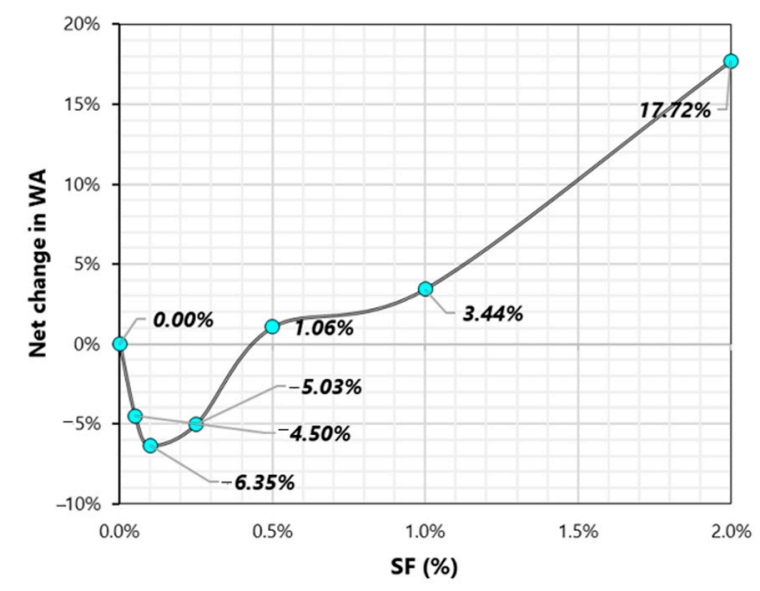

(b)

Figure 11. Water-absorption (WA) results (a) Variation of WA with SF dosage (b) Net change in WA with varying SF dosage.

Figure 12 shows the effect of MS on WA capacity of concrete. MS brings down the WA capacity of concrete significantly. As extremely fine particles of MS fill the gaps left between cement particles, the overall density of matrix undergoes improvement. MS can reduce the pore-size at the ITZ between fiber and matrix. MS can nullify the negative effect of SF on WA. These results implicate an important role of MS in fibrous concretes. Since, fibers at medium to high volumes $(0.5-2 \%)$, increase the permeability which may favor the corrosion of SF. Corrosion of SF will significantly lower the 
performance of fibrous concrete over time. Therefore, the conjunctive use of fibers and MS can increase the durability life of fibrous concrete composites.

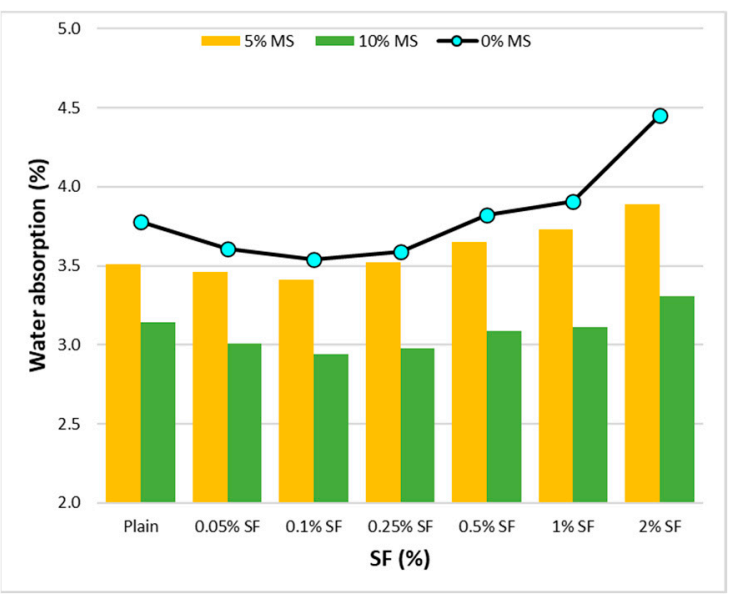

(a)

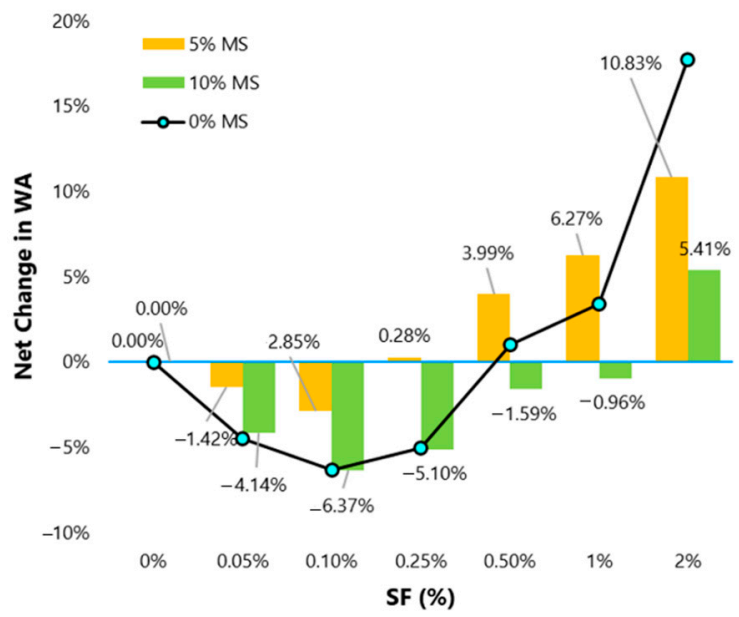

(b)

Figure 12. Water-absorption (WA) results (a) effect of MS on WA with varying SF dosage (b) effect of MS on the net change in WA with varying SF dosage.

\subsection{Chloride Ion Penetration (CIP)}

Figure 13 shows the effect of SF content on the CIP of concrete. CIP results also experience changes similar to WA with the variation of SF content. CIP undergoes reduction when fiber dose changes from 0 to $0.1 \%$. Since there is no involvement of forced electrical transfer of chloride ions in the immersion technique high conductivity of SF does not play any role in determining the CIP resistance of concrete. CIP resistance improvement at low fiber volumes can be ascribed to a reduction in the WA capacity of concrete. On the other hand, reduction in CIP resistance at high fiber volumes $(1 \%$ and $2 \%$ ) can be blamed to an increase in porosity or absorption capacity of the matrix. At $2 \%$ SF, CIP of concrete is about $18 \%$ higher than that of the plain concrete. Since chloride-induced corrosion is usually experienced in most concrete structures, low chloride permeability resistance of fibrous concretes (especially with a high volume of fibers) can create durability issues which must be considered while designing a concrete mix.

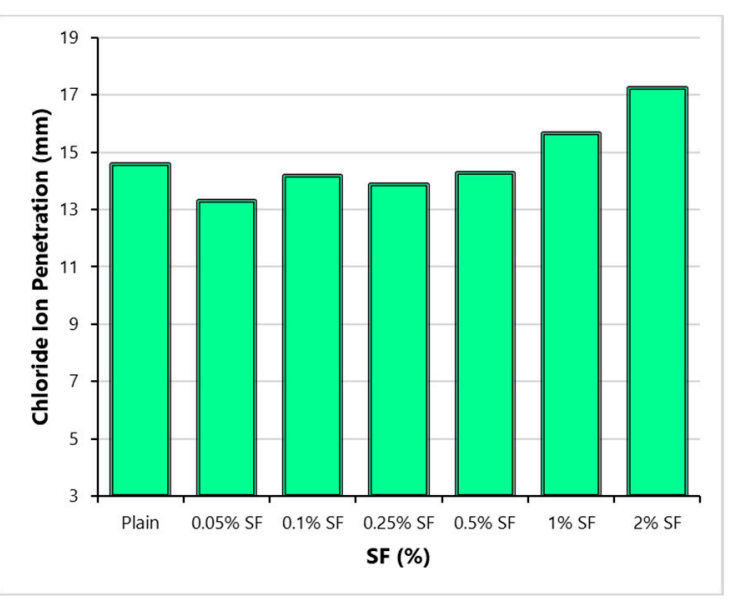

(a)

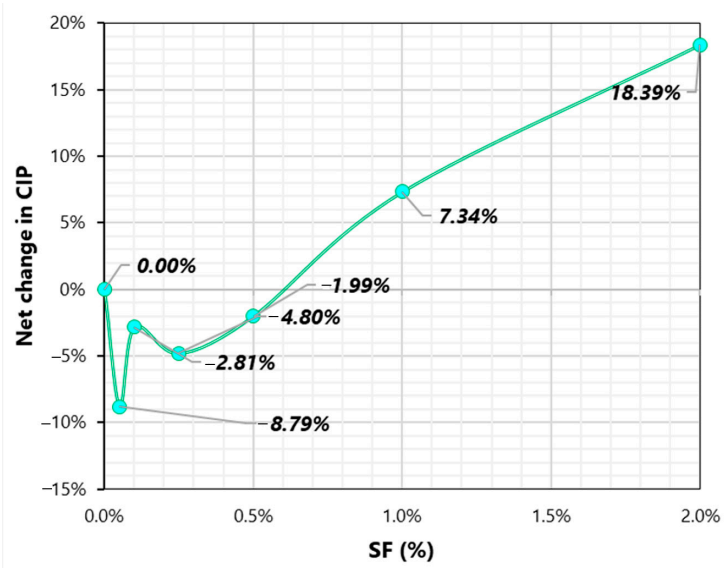

(b)

Figure 13. Chloride-ion penetration (CIP) results (a) Variation of CIP with SF dosage (b) Net change in CIP with varying SF dosage. 
Figure 14 shows the effect of MS content on the CIP. The addition of $5 \% \mathrm{MS}$ and $10 \% \mathrm{MS}$ brings down the CIP by $23 \%$ and $33 \%$, respectively w.r.t plain concrete (without MS). The behavior of WA and CIP with the addition of MS is very similar because MS substantially reduces the volume of permeable voids [2]. As fibrous concretes struggle with the issue of low CIP resistance at high fiber doses, MS can be a befitting addition to enhance the imperviousness of concrete. With 5 or $10 \% \mathrm{MS}$, high fiber volume concretes show lower CIP than control concrete (see Figure 14a).

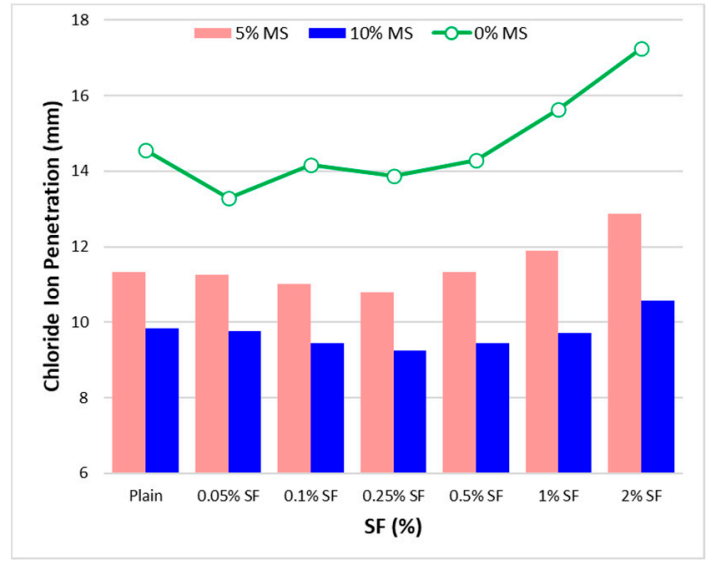

(a)

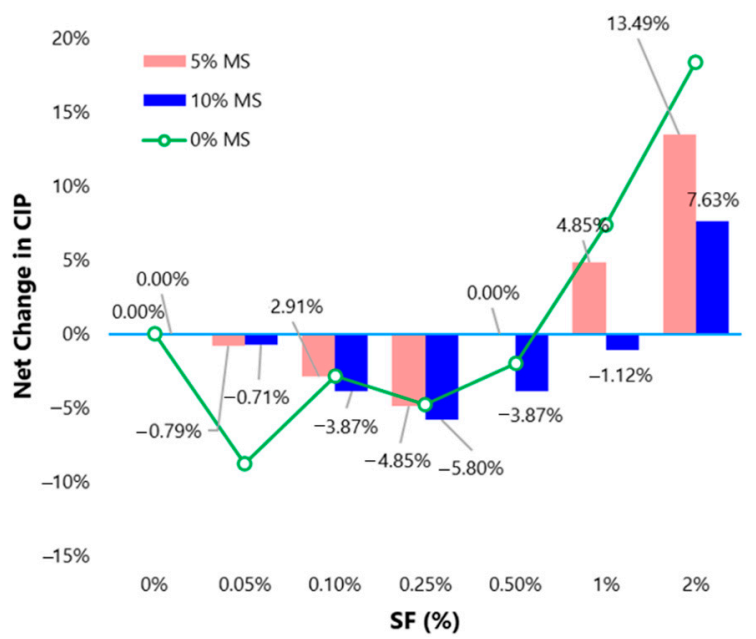

(b)

Figure 14. Chloride-ion penetration (CIP) results (a) effect of MS on CIP with varying SF dosage (b) effect of MS on the net change in CIP with varying SF dosage.

By constricting the microchannels across the ITZs at fibers, MS can efficiently minimize the degrading effect of fibers on CIP. Almost all engineering properties of concrete depend on the growth and density of microstructure i.e., strength and permeability characteristics. CS, CIP, and WA are correlated with each other in Figure 15. The surface plot shows a general trend that CS is inversely related to both WA and CIP. All data points in Figure 15, congregate near-surface plot which means CS, CIP and WA are strongly correlated (R2 $>0.8)$ and models developed to predict these parameters from each other can be formulated for design purposes. 


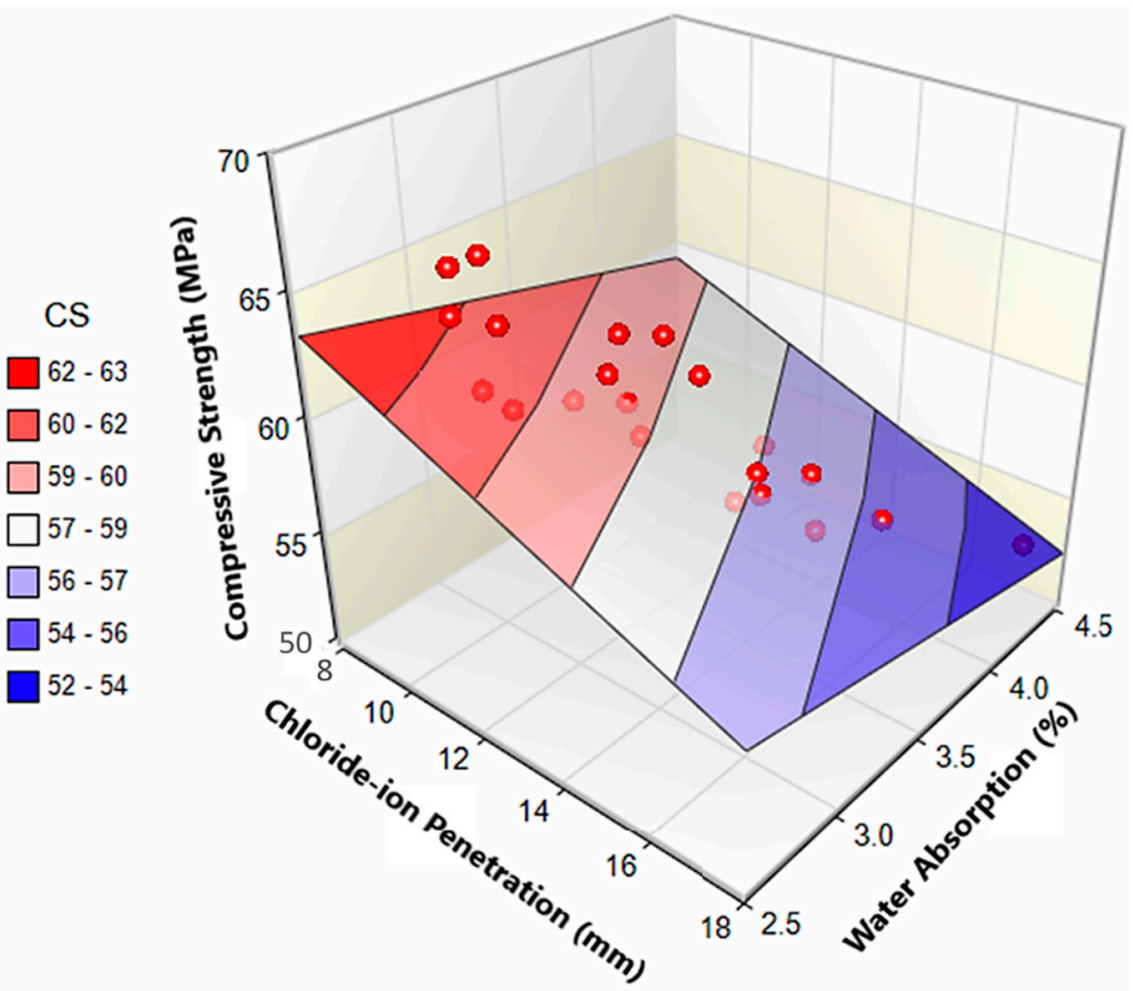

Figure 15. Correlation between CS, CIP and WA.

\section{Conclusions}

This study evaluates the influence of a wide range of SF doses on the basic engineering characteristics of high strength concrete. It also explores the modifications of SF-reinforced concrete properties with micro-silica (MS). Following important conclusions can be taken from this research:

(1) Fibers have mixed effects on compressive strength (CS). The positive effect of SF on CS is observed only at small doses. A high-volume dose of SF negatively affects CS. MS improves the utilization of SF in advancing the CS of concrete.

(2) Similar to CS results, modulus of elasticity (MOE) also shows mixed behavior with varying fiber dose. Low volumes $(0.05-0.5 \%)$ of SF are beneficial to MOE, whereas high volumes $(1-2 \%)$ are detrimental to MOE. MS shows synergistic effects with SF on MOE. SF doses of $0.5 \%$ produce optimum MOE and CS. The addition of MS is highly useful compared to SF addition if the increment in CS or MOE is desired.

(3) Splitting-tensile strength (STS) increases up to $36 \%$ with the rising dose of SF (0 to $2 \%$ ). There is no significant achievement in STS when SF doses increased beyond 1\%. STS experience more gain than CS and MOE at all doses of SF. MS improves the net gain in STS due to SF addition. The combined addition of $10 \% \mathrm{MS}$ and $1 \%$ SF produces concrete with $60 \%$ more STS than plain concrete.

(4) Considering the combined behavior of CS, MOE, and STS, 1\%SF can be taken as the optimum dose for high strength concrete.

(5) At low to medium fiber doses $(0.05-0.25 \%)$, the WA of concrete was slightly lower than that of the plain concrete. Whereas high fiber doses $(0.5-1 \%)$ are determinantal to the imperviousness of concrete. The positive effect of low fiber volumes is very negligible compared to that of the MS. MS can play a key role in downing the WA capacity of high fiber volume concretes.

(6) Similar to WA, chloride-ion penetration (CIP) experiences a small reduction of $0.05-0.25 \% \mathrm{SF}$. The detrimental effect of high fiber dose can be minimized by MS addition. With the help of $10 \% \mathrm{MS}, 2 \% \mathrm{SF}$ concrete shows a significant $25 \%$ lower CIP compared to plain concrete. 


\section{Future Research}

Effect of micro-silica on the interfacial zones of fibers should be studied using scanning electron microscopy. Moreover, combined effect of MS and SF on different strength classes of concrete should also be investigated and compared. Effect of different MS contents on the freeze-thaw and corrosion resistance of SFRC can also be studied.

Author Contributions: Conceptualization, B.A. and B.H.; methodology, B.A. and B.H.; software, B.A. and B.H.; validation, R.K. and B.H.; formal analysis, B.A., R.K., B.H., R.A., A.R., A.M., R.M. and H.A.; investigation, B.A., B.H.; resources, B.A., R.K., B.H., R.A., A.R., A.M., R.M. and H.A.; data curation, B.A.; writing-original draft preparation, B.A. and B.H.; writing-review and editing, R.K., B.H., R.A., A.R., A.M., R.M., B.H., M.F.U.-H. and H.A.; visualization, R.K., B.H., R.A., A.R., A.M., R.M., M.F.U.-H. and H.A.; supervision, R.K.; project administration, B.A., and R.K.; funding acquisition, R.A. All authors have read and agreed to the published version of the manuscript.

Funding: This research was funded by Deanship of scientific research, Prince Sattam bin Abdulaziz University, grant number No. 2020/01/16810.

Acknowledgments: This publication was supported by Deanship of scientific research, Prince Sattam bin Abdulaziz University under research project No. 2020/01/16810.

Conflicts of Interest: The authors declare no conflict of interest.

\section{Nomenclature}

$\begin{array}{ll}\text { CIP } & \text { Chloride Ion Penetration } \\ \text { CS } & \text { Compressive Strength } \\ \text { MOE } & \text { Modulus of Elasticity } \\ \text { MS } & \text { Micro-Silica } \\ \text { SF } & \text { Steel Fiber } \\ \text { STS } & \text { Splitting Tensile Strength } \\ \text { WA } & \text { Water Absorption }\end{array}$

\section{References}

1. Ali, B.; Qureshi, L.A. Influence of glass fibers on mechanical and durability performance of concrete with recycled aggregates. Constr. Build. Mater. 2019, 228, 116783. [CrossRef]

2. Ali, B.; Ahmed, H.H.; Qureshi, L.A.; Kurda, R.; Hafez, H.; Mohammed, H.; Raza, A. Enhancing the Hardened Properties of Recycled Concrete (RC) through Synergistic Incorporation of Fiber Reinforcement and Silica Fume. Materials 2020, 13, 4112. [CrossRef] [PubMed]

3. Koushkbaghi, M.; Kazemi, M.J.; Mosavi, H.; Mohseni, E. Acid resistance and durability properties of steel fiber-reinforced concrete incorporating rice husk ash and recycled aggregate. Constr. Build. Mater. 2019, 202, 266-275. [CrossRef]

4. Zain, M.; Mahmud, H.; Ilham, A.; Faizal, M. Prediction of splitting tensile strength of high-performance concrete. Cem. Concr. Res. 2002, 32, 1251-1258. [CrossRef]

5. Xie, J.; Li, J.; Lu, Z.; Li, Z.; Fang, C.; Huang, L.; Li, L. Combination effects of rubber and silica fume on the fracture behaviour of steel-fibre recycled aggregate concrete. Constr. Build. Mater. 2019, 203, 164-173. [CrossRef]

6. Cao, S.; Xue, G.; Yilmaz, E. Flexural Behavior of Fiber Reinforced Cemented Tailings Backfill under Three-Point Bending. IEEE Access 2019, 7, 139317-139328. [CrossRef]

7. Ali, B.; Qureshi, L.A.; Khan, S.U. Flexural behavior of glass fiber-reinforced recycled aggregate concrete and its impact on the cost and carbon footprint of concrete pavement. Constr. Build. Mater. 2020, 262, 120820. [CrossRef]

8. Wang, J.; Dai, Q.; Si, R.; Ma, Y.; Guo, S. Fresh and mechanical performance and freeze-thaw durability of steel fiber-reinforced rubber self-compacting concrete (SRSCC). J. Clean. Prod. 2020, 277, 123180. [CrossRef]

9. Qureshi, L.A.; Ali, B.; Ali, A. Combined effects of supplementary cementitious materials (silica fume, GGBS, fly ash and rice husk ash) and steel fiber on the hardened properties of recycled aggregate concrete. Constr. Build. Mater. 2020, 263, 120636. [CrossRef] 
10. Hussain, I.; Ali, B.; Akhtar, T.; Jameel, M.S.; Raza, S.S. Comparison of mechanical properties of concrete and design thickness of pavement with different types of fiber-reinforcements (steel, glass, and polypropylene). Case Stud. Constr. Mater. 2020, 13, e00429. [CrossRef]

11. Ahmad, W.; Farooq, S.H.; Usman, M.; Khan, M.; Ahmad, A.; Aslam, F.; Alyouef, R.; Alabduljabbar, H.; Sufian, M. Effect of Coconut Fiber Length and Content on Properties of High Strength Concrete. Materials 2020, 13, 1075. [CrossRef] [PubMed]

12. Ahmed, H.H.; Bogas, J.A. Influence of carbon nanotubes on steel-concrete bond strength. Mater. Struct. 2018, 51, 155. [CrossRef]

13. Hawreen, A.; Bogas, J.A.; Kurda, R.; Hawreen, A.; Bogas, J.A.; Kurda, R. Mechanical Characterization of Concrete Reinforced with Different Types of Carbon Nanotubes. Arab. J. Sci. Eng. 2019, 44, 8361-8376. [CrossRef]

14. Ali, B.; Qureshi, L.A.; Kurda, R. Environmental and economic benefits of steel, glass, and polypropylene fiber reinforced cement composite application in jointed plain concrete pavement. Compos. Commun. 2020, 22, 100437. [CrossRef]

15. Wu, Z.; Shi, C.; He, W.; Wu, L. Effects of steel fiber content and shape on mechanical properties of ultra high performance concrete. Constr. Build. Mater. 2016, 103, 8-14. [CrossRef]

16. Raza, S.S.; Qureshi, L.A.; Ali, B.; Raza, A.; Khan, M.M. Effect of different fibers (steel fibers, glass fibers, and carbon fibers) on mechanical properties of reactive powder concrete. Struct. Concr. 2020. [CrossRef]

17. Alabduljabbar, H.; Alyouef, R.; Alrshoudi, F.; Alaskar, A.; Fathi, A.; Mohamed, A.M. Mechanical Effect of Steel Fiber on the Cement Replacement Materials of Self-Compacting Concrete. Fibers 2019, 7, 36. [CrossRef]

18. Lee, S.F.; Jacobsen, S. Study of interfacial microstructure, fracture energy, compressive energy and debonding load of steel fiber-reinforced mortar. Mater. Struct. 2011, 44, 1451-1465. [CrossRef]

19. Li, V.C.; Wu, H.-C.; Chan, Y.-W. Effect of Plasma Treatment of Polyethylene Fibers on Interface and ementitious Composite Properties. J. Am. Ceram. Soc. 2005, 79, 700-704. [CrossRef]

20. Teng, S.; Afroughsabet, V.; Ostertag, C.P. Flexural behavior and durability properties of high performance hybrid-fiber-reinforced concrete. Constr. Build. Mater. 2018, 182, 504-515. [CrossRef]

21. Afroughsabet, V.; Biolzi, L.; Ozbakkaloglu, T. Influence of double hooked-end steel fibers and slag on mechanical and durability properties of high performance recycled aggregate concrete. Compos. Struct. 2017, 181, 273-284. [CrossRef]

22. Afroughsabet, V.; Ozbakkaloglu, T. Mechanical and durability properties of high-strength concrete containing steel and polypropylene fibers. Constr. Build. Mater. 2015, 94, 73-82. [CrossRef]

23. Xie, J.; Zhang, Z.; Lu, Z.; Sun, M. Coupling effects of silica fume and steel-fiber on the compressive behaviour of recycled aggregate concrete after exposure to elevated temperature. Constr. Build. Mater. 2018, 184, 752-764. [CrossRef]

24. Wang, J.; Xie, J.; He, J.; Sun, M.; Yang, J.; Li, L. Combined use of silica fume and steel fibre to improve fracture properties of recycled aggregate concrete exposed to elevated temperature. J. Mater. Cycles Waste Manag. 2020, 22, 1-16. [CrossRef]

25. Carneiro, J.A.; Lima, P.R.L.; Leite, M.B.; Filho, R.D.T. Compressive stress-strain behavior of steel fiber reinforced-recycled aggregate concrete. Cem. Concr. Compos. 2014, 46, 65-72. [CrossRef]

26. Song, W.; Yin, J. Hybrid effect evaluation of steel fiber and carbon fiber on the performance of the fiber reinforced concrete. Materials 2016, 9, 704. [CrossRef]

27. Wu, Z.; Khayat, K.H.; Khayat, K. Influence of silica fume content on microstructure development and bond to steel fiber in ultra-high strength cement-based materials (UHSC). Cem. Concr. Compos. 2016, 71, 97-109. [CrossRef]

28. C01 Committee. Specification for Portland Cement; ASTM International: West Conshohocken, PA, USA, 2018.

29. ASTM International. ASTM-C39, Standard Test Method for Compressive Strength of Cylindrical Concrete Specimens; ASTM International: West Conshohocken, PA, USA, 2015.

30. ASTM International. ASTM-C469, Standard Test Method for Static Modulus of Elasticity and Poisson's Ratio of Concrete in Compression; ASTM International: West Conshohocken, PA, USA, 2014.

31. ASTM International. ASTM-C496, Standard Test Method for Splitting Tensile Strength of Cylindrical Concrete Specimens; ASTM International: West Conshohocken, PA, USA, 2017.

32. ASTM International. ASTM-C642-13, Standard Test Method for Density, Absorption, and Voids in Hardened Concrete; ASTM International: West Conshohocken, PA, USA, 2013. 
33. Ali, B.; Qureshi, L.A. Durability of recycled aggregate concrete modified with sugarcane molasses. Constr. Build. Mater. 2019, 229, 116913. [CrossRef]

34. Das, C.S.; Dey, T.; Dandapat, R.; Mukharjee, B.B.; Kumar, J. Performance evaluation of polypropylene fibre reinforced recycled aggregate concrete. Constr. Build. Mater. 2018, 189, 649-659. [CrossRef]

35. Chan, R.; Santana, M.A.; Oda, A.M.; Paniguel, R.C.; Vieira, L.B.; Figueiredo, A.D.; Galobardes, I. Analysis of potential use of fibre reinforced recycled aggregate concrete for sustainable pavements. J. Clean. Prod. 2019, 218, 183-191. [CrossRef]

36. Ali, B.; Raza, S.S.; Hussain, I.; Iqbal, M. Influence of different fibers on mechanical and durability performance of concrete with silica fume. Struct. Concr. 2020, 201900422. [CrossRef]

37. Chan, Y.-W.; Chu, S.-H. Effect of silica fume on steel fiber bond characteristics in reactive powder concrete. Cem. Concr. Res. 2004, 34, 1167-1172. [CrossRef]

38. Lee, S.-C.; Oh, J.-H.; Cho, J.-Y. Compressive Behavior of Fiber-Reinforced Concrete with End-Hooked Steel Fibers. Materials 2015, 8, 1442-1458. [CrossRef] [PubMed]

39. Ou, Y.-C.; Tsai, M.-S.; Liu, K.-Y.; Chang, K.-C. Compressive Behavior of Steel-Fiber-Reinforced Concrete with a High Reinforcing Index. J. Mater. Civ. Eng. 2012, 24, 207-215. [CrossRef]

40. Dinh-Cong, D.; Keykhosravi, M.H.; Alyousef, R.; Salih, M.N.A.; Nguyen, H.; Alabduljabbar, H.; Alaskar, A.; Alrshoudi, F.; Poi-Ngian, S. The effect of wollastonite powder with pozzolan micro silica in conventional concrete containing recycled aggregate. Smart Struct. Syst. 2019, 24, 541-552.

41. Afroughsabet, V.; Biolzi, L.; Monteiro, P.J. The effect of steel and polypropylene fibers on the chloride diffusivity and drying shrinkage of high-strength concrete. Compos. Part B Eng. 2018, 139, 84-96. [CrossRef]

42. Li, D.; Liu, S. The influence of steel fiber on water permeability of concrete under sustained compressive load. Constr. Build. Mater. 2020, 242, 118058. [CrossRef]

Publisher's Note: MDPI stays neutral with regard to jurisdictional claims in published maps and institutional affiliations. 